\title{
Age- and sex-related regional compressive strength characteristics of human lumbar vertebrae in osteoporosis
}

\author{
Márta Kurutz' \\ Judit Donáth ${ }^{3}$ \\ Miklós Gálos ${ }^{2}$ \\ Péter Varga' \\ Béla Fornet ${ }^{4}$ \\ 'Department of Structural Mechanics; \\ 2Department of Construction \\ Materials, Budapest University \\ of Technology and Economics, \\ Budapest, Hungary; ${ }^{3}$ Department \\ of Reumatology, National Institute \\ for Reumatology, Budapest, Hungary; \\ ${ }^{4}$ Department of Radiology, County \\ Hospital András Jósa, Nyiregyháza, \\ Hungary
}

Objective: To obtain the compressive load bearing and energy absorption capacity of lumbar vertebrae of osteoporotic elderly for the everyday medical praxis in terms of the simple diagnostic data, like computed tomography (CT), densitometry, age, and sex.

Methods: Compressive test of 54 osteoporotic cadaver vertebrae L1 and L2, 16 males and 38 females (age range 43-93, mean age 71.6 \pm 13.3 years, mean bone mineral density (BMD) $0.377 \pm 0.089 \mathrm{~g} / \mathrm{cm}^{2}$, mean T-score $-5.57 \pm 0.79$, Z-score $-4.05 \pm 0.77$ ) was investigated. Based on the load-displacement diagrams and the measured geometrical parameters of vertebral bodies, proportional, ultimate and yield stresses and strains, Young's modulus, ductility and energy absorption capacity were determined. Three vertebral regions were distinguished: superior, central and inferior regions, but certain parameters were calculated for the upper/ lower intermediate layers, as well. Cross-sectional areas, and certain bone tissue parameters were determined by image analysis of CT pictures of vertebrae. Sex- and age-related decline functions and trends of strength characteristics were determined.

Results: Size-corrected failure load was $15 \%-25 \%$ smaller in women, proportional and ultimate stresses were about $30 \%-35 \%$ smaller for women in any region, and $20 \%-25 \%$ higher in central regions for both sexes. Young's moduli were about $30 \%$ smaller in women in any region, and 20\%-25\% smaller in the central region for both sexes. Small strains were higher in males, large strains were higher in females, namely, proportional strains were about $25 \%$ larger in men, yield and ultimate strains were quasi equal for sexes, break strains were $10 \%$ higher in women. Ultimate energy absorption capacity was $10 \%-20 \%$ higher in men; the final ductile energy absorption capacity was quasi equal for sexes in all levels. Age-dependence was stronger for men, mainly in central regions (ultimate load, male: $r=-0.66, p<0.01$, female: $r=-0.52, p<0.005$; ultimate stress, male: $r=-0.69, p<0.01$, female: $r=-0.50, p<0.005$; Young's modulus, male: $\mathrm{r}=-0.55, \mathrm{p}<0.05$, female: $\mathrm{r}=-0.52, \mathrm{p}<0.005$, ultimate stiffness, male: $\mathrm{r}=-0.58, \mathrm{p}<0.05$, female: $\mathrm{r}=-0.35, \mathrm{p}<0.03$, central ultimate absorbed energy density, male: $\mathrm{r}=-0.59, \mathrm{p}<0.015$, female: $\mathrm{r}=-0.29, \mathrm{p}<0.08)$.

Conclusions: For the strongly osteoporotic population (BMD $<0.4 \mathrm{~g} / \mathrm{cm}^{2}$, T-score $<-4$ ) the statical variables (loads, stresses) showed significant correlation; mixed variables (stiffness, Young's modulus, energy) showed moderate correlation; kinematical variables (displacements, strains) showed no correlation with age. The strong correlation of men between BMD and aging $(\mathrm{r}=-0.82, \mathrm{p}<0.001)$ and betwen BMD and strength parameters $(\mathrm{r}=0.8-0.9, \mathrm{p}<0.001)$ indicated linear trends in age-related strength loss for men; however, the moderate correlation of women between BMD and aging $(r=-0.47, \mathrm{p}<0.005)$ and between BMD and strength parameters $(\mathrm{r}=0.4-0.5, \mathrm{p}<0.005)$ suggested the need of nonlinear (quadratic) approximation that provided the better fit in age-related strength functions of females modelling postmenopausal disproportionalities.

Keywords: osteoporosis, human lumbar vertebral body, regional compressive strength, load, stress, strain, young's modulus, energy absorption capacity, age- and sex-dependence 


\section{Introduction}

Mosekilde (2000) demonstrated that age is the major determinant of vertebral bone strength, mass, and microarchitecture. In the last two decade many papers deal with aging of vertebral bone in aspect of geometry, bone mineral density (BMD), mass, bone architecture and compressive load-bearing capacity. Some papers consider the effect of aging and sex on the compressive strength characteristics of vertebrae. Mosekilde and colleagues (1987) obtained high correlation for age-related decrease of vertical compressive strength of vertebral trabecular bone. Duan and colleagues (2001) found age-related gender differences in stresses, Mori (1994) found high correlation between aging and compressive Young's modulus of lumbar vertebrae. Keaveny and Yeh (2002) found no evidence of any clinically relevant sex differences in the effect of age on the compressive strength of vertebral trabecular bone.

Some authors discuss the effect of age- and sex-related increase of vertebral cross-sectional area (CSA). According to Mosekilde and Mosekilde (1986) CSA increases significantly with aging, however, Mosekilde (2000) found it mainly in men. Duan and colleagues (2001) obtained that veretebral stresses decreased with aging more in men, due to their more increasing CSA. Ebbesen and colleagues (1999a) found that females had smaller vertebral bodies leading to lower maximum compressive load at all ages, whereas maximum compressive stress showed no gender-related differences. These results may be extended to strongly osteoporotic population, completed by a size-corrected analysis.

Some papers consider the regional inhomogeneity inside the vertebral body. Gong and colleagues (2005) found significant differences in regional morphometry of vertebral cancellous bones with aging. Briggs and colleagues (2004) discussed age-related subregional density differences. Banse and colleagues (2001) aimed to identify the weakest parts of the cancellous bone. Keller and colleagues (1992) described regional variations in cancellous bone morphology within the vertebral centrum. These results may be completed by age- and sex-related regional compressive load-bearing and energy absorption capacity of strongly osteoporotic population.

Functions of age-related decrease of BMD and compressive strength characteristics are generally considered linear, like by McCaldren and colleagues (1997) in compressive strength and apparent density of cancellous bone. Ebbesen and colleagues (1999a) concluded that the decline in vertebral bone mass with age was parallel for sexes. Nevertheless, some authors consider nonlinear age-dependence of BMD or strength properties, distinguishing sexes. Mosekilde (1998) stated that changes in decline trends of vertebral strength and density in certain life periods might be important in fracture risk. Blunt and colleagues (1994) concluded that BMD decreased significantly with age in both sexes, but the slope of loss was steeper in women in special life period. Diaz Curiel and colleagues (1997) obtained nonuniform change in BMD-age curves of lumbar spine in different life periods of healthy women. Warming and colleagues (2002) stated that the bone loss before menopause was nearly tripled ten years later in healthy women. Greer and colleagues (2003) presented a mathematical model for the decline of BMD with aging, suggesting an exponential decay process of bone loss beginning at menopause. These results can be completed by nonlinear analysis of age-related regional strength parameters of osteoporotic women.

\section{Methods}

Fifty-four strongly osteoporotic (BMD $<0.4 \mathrm{~g} / \mathrm{cm}^{2}$, T-score $<-4)$ cadaver lumbar vertebrae $31 \mathrm{~L} 1$ and $23 \mathrm{~L} 2$ without posterior elements (age range 43-93 years, mean age $71.6 \pm 13.3$ year, mean BMD $0.377 \pm 0.089 \mathrm{~g} / \mathrm{cm}^{2}$, mean T-score $-5.57 \pm 0.79$, Z-score $-4.05 \pm 0.77$ ) were tested, 16 males (age range 47-87 years, mean age 65.6 \pm 12.6 year, mean BMD $0.446 \pm 0.088 \mathrm{~g} / \mathrm{cm}^{2}$, mean T-score $-5.41 \pm 0.84$, Z-score $-4.72 \pm 0.64$ ) and 38 females (age range $43-93$ years, mean age $74.2 \pm 12.9$ year, mean BMD $0.347 \pm 0.072 \mathrm{~g} / \mathrm{cm}^{2}$, mean T-score $-5.63 \pm 0.77, \mathrm{Z}$-score $-3.75 \pm 0.63$ ). The storage of vertebrae before densitometry and compressive test was in formaline solution.

\section{Densitometry, CT, compressive test}

Bone mineral density (BMD) was measured by Hologic QDR Elite equipment, by using Spine program and Array manner. In vitro measurement precision was $1 \%$. The measurement was repeated three times and the average of them was used. The position of the vertebral bodies was the same by every scanning. The upperline of the vertebral body was taken down on the table and the middle line of the table was the center line of the vertebral body. Only the vertebral body was measured, the ROI followed the vertebral contours. The final result was calculated as $\mathrm{BMC} \mathrm{gr} / \mathrm{ROI} \mathrm{cm}^{2}=\mathrm{BMD} \mathrm{gr} / \mathrm{cm}^{2}$.

CT examinations were taken by Hitachi W 2000 CT equipment. The scanning was done in axial and coronal views. Technical details were: slice thickness $1 \mathrm{~mm}$, stepping $1 \mathrm{~mm}, 40$ contigous slices; $120 \mathrm{kV}, 175 \mathrm{~mA}$, scanning time $2 \mathrm{~s}$; filter $1 \mathrm{H}$; HR spine protokoll, matrix: $512 * 512$. Images were digitally stored and archived. 
Cross-sectional areas (CSAs) were measured by analysing individual 2D sections of the CT database in grayscale image format. Evaluation process was performed with software by means of a graphical user interface developed in MATLAB environment.

For mechanical testing, the two end-plates of vertebrae were cut, so that the cuts had to be parallel. Thus, the original height of vertebrae decreased by two times $0.5-3.0 \mathrm{~mm}$ (mean $1.66 \mathrm{~mm}$ ). The original and reduced heights and the end CSAs were measured.

The loading was applied in the superoinferior direction of vertebrae. The compressive test was performed on each vertebra up to the break. No cyclic loading and no unloading were performed. The measuring limit of the tester was $12.5 \mathrm{kN}$ with accuracy of $3 \%$. The compressive deformations, that is, the shortenings were measured in three points, by angle of 120 degrees from each other. Loading forces and relative

A

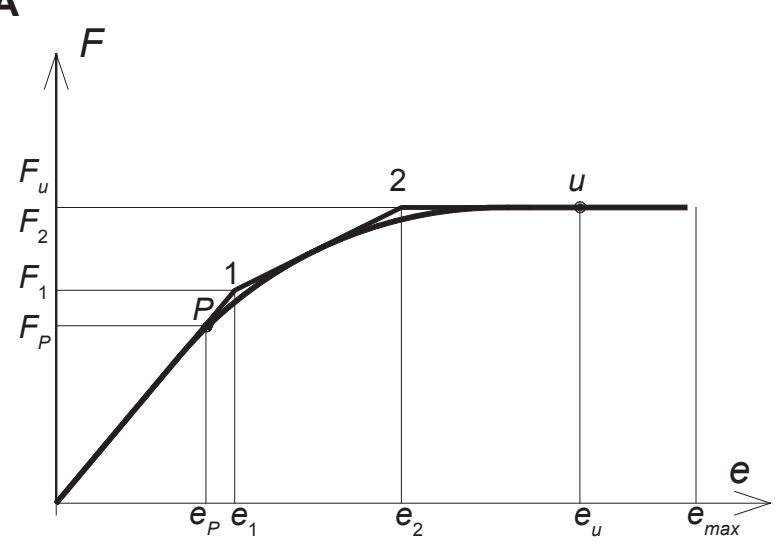

Type A

B

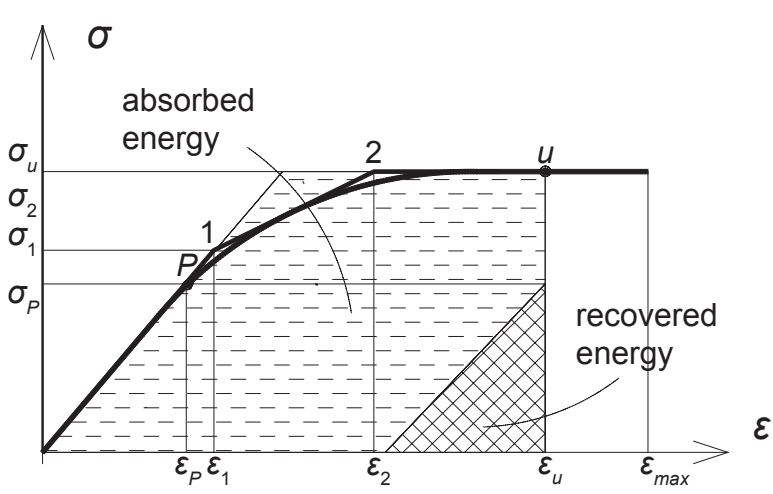

Type A displacements of the two end-plates were registered and plotted to a load-displacement diagram.

\section{Compressive strength characteristics}

The automatically plotted load-displacement diagrams were linearized (Figure 1a). Two classes of load-displacement diagrams were distinguished: type $A$ with monotone decreasing stiffness and lower failure load; type $B$ with first increasing then decreasing stiffness and higher failure load. The related stress-strain diagrams with absorbed and recovered energy densities are seen in Figure 1b. To avoid size effect, load values were divided by the actual volume of vertebrae; similarly, instead of energy, the density of energy was considered.

By considering the associated coordinates of characteristic points in Figures $1 \mathrm{a}$ and $1 \mathrm{~b}$, the following mechanical characteristics were measured:

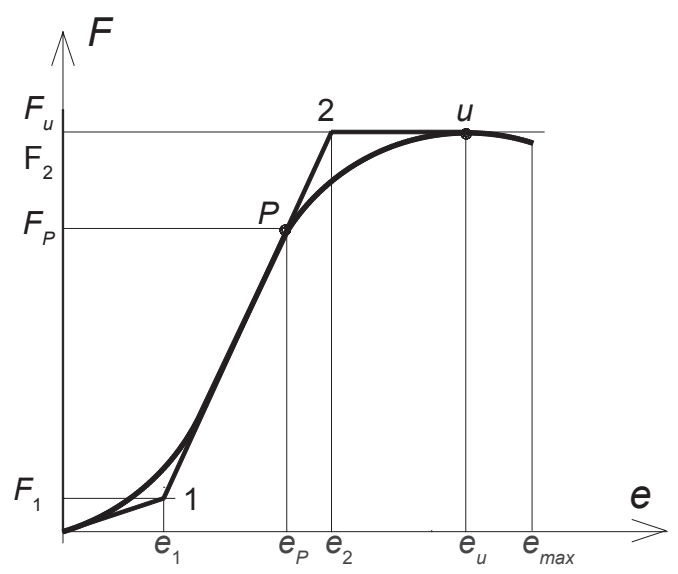

Type B

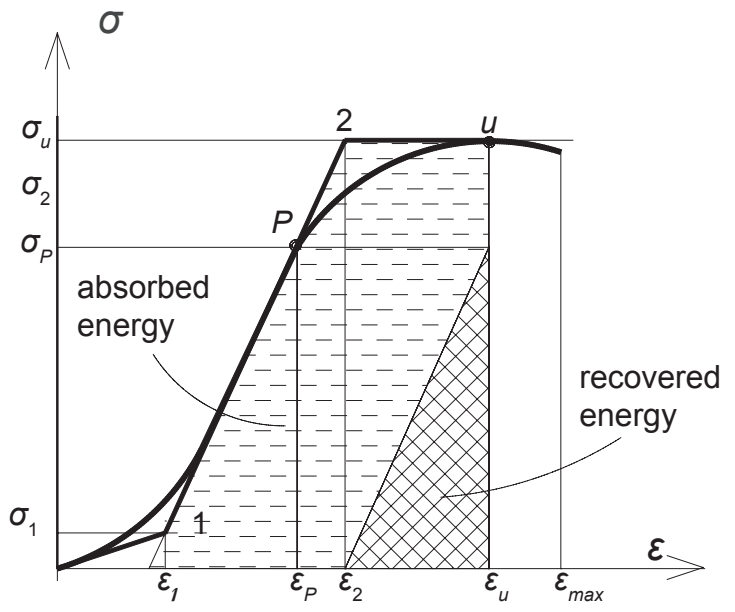

Type B

Figure I Typical load-displacement and stress-strain diagrams with the related strain energy densities of vertebrae. A) load-displacement diagrams with linearization. B) linearized stress-strain diagrams with absorbed and recovered energy densities, the latter calculated at ultimate strains and proportional stresses. 
- proportional loads and displacements $F_{p}$ and $e_{p}$;

- ultimate (failure) loads and displacements $F_{u}$ and $e_{u}$;

- maximum (break) displacements $e_{\max }$ after failure;

- and the following strength characteristics were calculated:

- size-corrected proportional loads:

$$
q_{p}=\frac{F_{p}}{V}
$$

- $\quad$ size-corrected ultimate loads:

$$
q_{u}=\frac{F_{u}}{V}
$$

- proportional stresses and strains:

$$
\sigma=\frac{F_{p}}{A}, \quad \mathcal{E}_{p}=\frac{e_{p}}{h}
$$

- ultimate (failure) stresses and strains:

$$
\sigma_{u}=\frac{F_{u}}{A}, \quad \varepsilon_{u}=\frac{e_{u}}{h} ;
$$

- plastic yield stresses and strains:

$$
\sigma_{y}=\sigma_{2}=\frac{F_{2}}{A}, \quad \varepsilon_{y}=\varepsilon_{2}=\frac{e_{2}}{h}
$$

- maximal (break) strains:

$$
\varepsilon_{\max }=\frac{e_{\max }}{h}
$$

- ductility (maximum plastic deformability):

$$
\varepsilon_{d}=\varepsilon_{\max }-\varepsilon_{y} .
$$

To follow the stress and energy distribution along the height $h$ of vertebrae, we distinguished five horizontal regions: superior, central, inferior and intermediate levels between central and superior/inferior levels, characterized by the relating cross-sectional areas $A_{\text {sup }}, A_{\text {centr }}, A_{\text {inf }}$ and $A_{\text {supint }}, A_{\text {inf int }}$, respectively, considered as $A$ in (3-5). In (1-2) $V$ is the volume of the specimen, calculated by

$$
V=\frac{A_{\text {supint }}+A_{\text {inf int }}}{2} \cdot h .
$$

Furthermore, the following stiffness parameters were calculated:

- proportional and ultimate stiffnesses:

$$
K_{p}=\frac{F_{p}}{e_{p}}, \quad K_{u}=\frac{F_{u}}{e_{u}} ;
$$

- Young's elastic modulus, as the tangent of the dominant linear part of diagrams (Figure 1b):

$$
E=\left\{\begin{array}{cl}
\frac{\sigma_{p}}{\varepsilon_{p}} & \text { for type } A \\
\frac{\sigma_{2}-\sigma_{1}}{\varepsilon_{2}-\varepsilon_{1}} & \text { for type } B
\end{array}\right.
$$

The calculated energy densities for both diagrams type $A$ and $B$ were as follows:

- total energy density at ultimate strains:

$$
W_{\text {tot }}^{u}=\frac{\sigma_{1} \cdot \mathcal{E}_{1}}{2}+\frac{\left(\varepsilon_{2}-\varepsilon_{1}\right) \cdot\left(\sigma_{1}+\sigma_{2}\right)}{2}+\frac{\left(\varepsilon_{u}-\varepsilon_{2}\right) \cdot\left(\sigma_{2}+\sigma_{u}\right)}{2} ;
$$

- total energy density at maximal (ductile) strains:

$$
W_{t o t}^{d}=W_{t o t}^{u}+\left(\varepsilon_{\max }-\varepsilon_{u}\right) \cdot \sigma_{u}
$$

- recoverable elastic energy density at proportional stresses:

$$
W_{e l}^{p}=\frac{\sigma_{p}^{2}}{2 E} ;
$$

- recoverable elastic energy density at ultimate stresses:

$$
W_{e l}^{u}=\frac{\sigma_{u}^{2}}{2 E}
$$

- absorbed energy density at ultimate strains:

$$
W_{a b s}^{u}=W_{t o t}^{u}-W_{e l}^{p}
$$

- absorbed ductile energy density at maximal strains:

$$
W_{a b s}^{d}=W_{t o t}^{d}-W_{e l}^{p} .
$$

Stresses (3-5) and energy densities (11-16) were calculated separately for the five regions. Since regional strains were not known, Young's moduli were considered constant, calculated from the average of the superior and inferior stresses.

\section{Statistical analysis}

Pearson correlations were calculated between measured or calculated strength parameters and age. In most cases linear regression analysis was applied when evaluating the relationships between two parameters, such as strength parameters and aging. In some cases, nonlinear trend lines were performed where the curves with highest $R^{2}$ numbers were accepted as best approximation. Two-tailed $t$-test of significance was used for mean values of strength 
parameters of the different regions and sexes. The confidence interval was set at $95 \%$ and the $P$ values $<0.05$ were considered significant. The analyses were performed separately for vertebrae L1 and L2 and also for L1-L2 together, each for the whole set of vertebrae and separately for sexes.

\section{Results}

The comparison of mean age, density, geometry and some compressive strength data of vertebrae L1 and L2 is seen in Table 1, with age-correlation. In Table 2 the mean age, density and geometry of the united vertebrae L1-L2 is illustrated by distinguishing the sexes, in correlation with age.

Table 3 shows the mean compressive strength characteristics of vertebrae L1-L2, namely, the loads, regional stresses, Young's moduli and stiffness data, by distinguishing the sexes. Table 4 lists the strains with recoverable and absorbed energy densities. Both Tables 3 and 4 contain the correlation of the listed parameters with age, BMD and T-score.

Figure 2 illustrates the change of regional CSAs versus aging and sex. Figure 2a illustrates the mean regional CSAs for sexes. Age-related increase of superior CSA is seen in Figure $2 b$, by distinguishing the sexes. Similar tendencies are obtained for the other cross-sectional levels of vertebrae: women have larger yearly increase of CSA, seen in Figure 2c, where the yearly increase trends of regional CSAs are illustrated. Figure $2 \mathrm{~d}$ shows the sum of all agerelated increase of regional CSAs during 50 years between 43-93 years. Here the percents are related to the CSAs of age 43 .

In Figure 3 the measured age-related decrease trends of ultimate load can be seen, by using linear regression for both sexes.
The trends of ultimate load and trends of size-corrected load are illustrated in Figures 3a, 3b, respectively.

Figure 4 shows the age-related decrease of regional ultimate stresses of vertebrae L1-L2, by distinguishing the sexes. In Figure 4a linear decrease trends of central ultimate stresses with aging can be seen. Similar tendencies are valid for the other vertebral levels, as well, seen in Figure 4b, where the age-related yearly decrease trends of regional ultimate stresses are distinguished for the sexes. The total decrease percents of regional ultimate stresses during 50 years between 43-93 years are seen in Figure 4c.

For the lack of nonuniform distribution of strains along the height of vertebrae, the Young's modulus was considered constant for each vertebra. Figures $5 \mathrm{a}$ and $5 \mathrm{~b}$ illustrates the age-related linear decline of Young's modulus and vertebral stiffness by distinguishing the sexes, respectively.

Energy absorption capacity was calculated both for ultimate and ductile strains, in order to illustrate the effect of ductility of vertebrae in the case of traumatic loading. Figures $6 \mathrm{a}$ and $6 \mathrm{~b}$ show the age-related decline trends of ultimate and ductile energy absorption capacities, respectively. Similar tendencies are valid for the other vertebral levels, too, seen in Figure 6c, where the age-related yearly loss of regional ultimate and ductile energy absorption capacities is distinguished for the sexes. The total loss of regional energy absorption capacities during 50 years between 43-93 years are seen in Figure 6d in percents of energy densities of age 43 .

The age-related loss of vertebral compressive load-bearing capacity depends on the age-related loss of vertebral bone density. In Figure 7 the direct effect of BMD on the compressive strength characteristics are illustrated. Figures $7 \mathrm{a}$, $7 \mathrm{~b}, 7 \mathrm{c}$, and $7 \mathrm{~d}$ shows the BMD-related increase of ultimate

Table I Comparing age, density, geometry, and strength data of vertebrae LI-L2

\begin{tabular}{|c|c|c|c|c|c|}
\hline \multirow[t]{2}{*}{ Age, density, geometry } & & \multicolumn{2}{|l|}{$\mathbf{L I}$} & \multicolumn{2}{|l|}{$\mathbf{L 2}$} \\
\hline & & Mean, SD & $\mathbf{r}_{\text {age }}$ & Mean, SD & $\mathbf{r}_{\text {age }}$ \\
\hline Mean age & years & $71.5 \pm 13.7$ & - & $71.7 \pm 13.0$ & - \\
\hline Bone mineral density, BMD & $\mathrm{g} / \mathrm{cm}^{2}$ & $0.374 \pm 0.085$ & -0.59 & $0.380 \pm 0.095$ & -0.69 \\
\hline T-score & - & $-5.27 \pm 0.66$ & -0.52 & $-5.97 \pm 0.79$ & -0.47 \\
\hline Superior cross-sectional area, $A_{\text {sup }}$ & $\mathrm{mm}^{2}$ & $|36| \pm 259$ & +0.20 & $1389 \pm 262$ & -0.20 \\
\hline Central cross-sectional area, $A_{\text {centr }}$ & $\mathrm{mm}^{2}$ & $1061 \pm 205$ & -0.03 & $1086 \pm 244$ & +0.09 \\
\hline Inferior cross-sectional area, $A_{\text {inf }}$ & $\mathrm{mm}^{2}$ & $1398 \pm 187$ & +0.08 & $|425 \pm 26|$ & +0.22 \\
\hline Height without end-plates, $h$ & $\mathrm{~mm}$ & $19.1 \pm 2.8$ & -0.13 & $21.0 \pm 3.3$ & -0.14 \\
\hline Volume of specimen, $V$ & $\mathrm{~mm}^{3}$ & $23421 \pm 6226$ & -0.05 & $26548 \pm 8381$ & +0.05 \\
\hline Ultimate load, $F_{u}$ & $N$ & $3161 \pm 1937$ & -0.63 & $3109 \pm 1898$ & -0.58 \\
\hline Central ultimate stress, $\sigma_{u, \text { centr }}$ & $\mathrm{MPa}$ & $3.01 \pm 1.73$ & -0.61 & $2.93 \pm 1.74$ & -0.57 \\
\hline Ultimate strain, $\varepsilon_{u}$ & $\%$ & $5.11 \pm 1.16$ & -0.06 & $4.99 \pm 1.43$ & -0.11 \\
\hline
\end{tabular}


Table 2 Age, density and geometry of vertebrae LI-L2 with age-correlation by distinguishing the sexes

\begin{tabular}{|c|c|c|c|c|c|c|c|}
\hline \multirow[t]{3}{*}{ Age, density, geometry } & & \multicolumn{6}{|l|}{ LI-L2 } \\
\hline & & \multicolumn{2}{|l|}{ Male $(n=16)$} & \multicolumn{2}{|c|}{ Female $(n=38)$} & \multicolumn{2}{|l|}{ Total $(n=54)$} \\
\hline & & Mean, SD & $r_{\text {age }}$ & Mean, SD & $r_{\text {age }}$ & Mean, SD & $r_{\text {age }}$ \\
\hline Mean age & years & $65.6 \pm 12.6$ & - & $74.2 \pm 12.9$ & - & $71.6 \pm 13.3$ & - \\
\hline $\begin{array}{l}\text { Bone mineral density, } \\
\text { BMD }\end{array}$ & $\mathrm{g} / \mathrm{cm}^{2}$ & $0.446 \pm 0.088$ & -0.82 & $0.347 \pm 0.072$ & -0.47 & $0.377 \pm 0.089$ & -0.63 \\
\hline T-score & - & $-5.41 \pm 0.84$ & $-0.7 \mid$ & $-5.63 \pm 0.77$ & -0.31 & $-5.57 \pm 0.79$ & -0.45 \\
\hline Z-score & - & $-4.72 \pm 0.64$ & -0.42 & $-3.75 \pm 0.63$ & 0.48 & $-4.05 \pm 0.77$ & 0.26 \\
\hline $\begin{array}{l}\text { Superior cross-sectional } \\
\text { area, } A_{\text {sup }}\end{array}$ & $\mathrm{mm}^{2}$ & $159 \mid \pm 210$ & 0.33 & $1272 \pm 212$ & 0.50 & $1366 \pm 256$ & 0.19 \\
\hline $\begin{array}{l}\text { Central cross-sectional } \\
\text { area, } A_{\text {centr }}\end{array}$ & $\mathrm{mm}^{2}$ & $1272 \pm 154$ & 0.27 & $990 \pm 189$ & 0.26 & $1073 \pm 221$ & 0.03 \\
\hline $\begin{array}{l}\text { Inferior cross-sectional } \\
\text { area, } A_{\text {inf }}\end{array}$ & $\mathrm{mm}^{2}$ & $1569 \pm 154$ & 0.17 & $1329 \pm 210$ & 0.37 & $1400 \pm 223$ & 0.12 \\
\hline $\begin{array}{l}\text { Height without } \\
\text { end-plates, } h\end{array}$ & $\mathrm{~mm}$ & $21.9 \pm 1.5$ & - & $19.0 \pm 3.3$ & - & $19.9 \pm 3.1$ & - \\
\hline Volume of specimen, $V$ & $\mathrm{~mm}^{3}$ & $31212 \pm 3588$ & - & $22033 \pm 6770$ & - & $24753 \pm 7317$ & - \\
\hline
\end{tabular}

Table 3 Proportional and ultimate loads and stresses with Young's moduli of lumbar vertebrae LI-L2 correlation with age and BMD by distinguishing the sexes

\begin{tabular}{|c|c|c|c|c|c|c|c|c|c|c|c|c|c|}
\hline \multirow{3}{*}{$\begin{array}{l}\text { Compressive loads } \\
\text { and stresses }\end{array}$} & & \multicolumn{12}{|l|}{ LI-L2 } \\
\hline & & \multicolumn{4}{|c|}{ Male $(n=16)$} & \multicolumn{4}{|c|}{ Female $(n=38)$} & \multicolumn{4}{|c|}{ Total $(n=54)$} \\
\hline & & Mean & $r_{\text {age }}$ & $r_{\text {BMD }}$ & $\mathbf{r}_{\text {Tscore }}$ & Mean & $\mathbf{r}_{\text {age }}$ & $r_{\text {BMD }}$ & $\mathbf{r}_{\text {Tscore }}$ & mean & $r_{\text {age }}$ & $r_{\text {BMD }}$ & $\mathbf{r}_{\text {Tscore }}$ \\
\hline Proportional load, $F_{p}$ & $\mathrm{~N}$ & 3212 & -0.60 & 0.83 & 0.76 & 1582 & -0.43 & 0.38 & 0.38 & 2065 & -0.55 & 0.69 & 0.51 \\
\hline Ultimate load, $F_{u}$ & $\mathrm{~N}$ & 4636 & -0.66 & 0.90 & 0.75 & 2509 & -0.52 & 0.47 & 0.40 & 3139 & -0.61 & 0.75 & 0.52 \\
\hline $\begin{array}{l}\text { Proportional size- } \\
\text { corrected load, } F_{p} / V\end{array}$ & $\mathrm{~N} / \mathrm{mm}^{3}$ & 0.106 & -0.61 & 0.84 & 0.81 & 0.082 & -0.37 & $0.4 I$ & 0.45 & 0.089 & -0.46 & 0.56 & 0.57 \\
\hline $\begin{array}{l}\text { Ultimate size-corrected } \\
\text { load, } F_{u} / V\end{array}$ & $\mathrm{~N} / \mathrm{mm}^{3}$ & 0.153 & -0.67 & 0.91 & 0.82 & 0.128 & -0.44 & 0.48 & 0.46 & 0.135 & -0.52 & 0.60 & 0.58 \\
\hline $\begin{array}{l}\text { Superior proportional } \\
\text { stress, } \sigma_{p, \text { sup }}\end{array}$ & $\mathrm{MPa}$ & 2.09 & -0.61 & 0.84 & 0.77 & 1.31 & -0.50 & 0.41 & 0.40 & 1.54 & -0.58 & 0.64 & 0.54 \\
\hline $\begin{array}{l}\text { Central proportional } \\
\text { stress, } \sigma_{p, \text { centr }}\end{array}$ & $\mathrm{MPa}$ & 2.58 & -0.62 & 0.85 & 0.78 & 1.68 & -0.42 & 0.42 & 0.42 & 1.95 & -0.53 & 0.64 & 0.55 \\
\hline $\begin{array}{l}\text { Inferior proportional } \\
\text { stress } \sigma_{p, \text { inf }}\end{array}$ & $\mathrm{MPa}$ & 2.09 & -0.60 & 0.84 & 0.77 & 1.25 & -0.47 & 0.41 & 0.41 & 1.50 & -0.56 & 0.65 & 0.55 \\
\hline $\begin{array}{l}\text { Superior ultimate } \\
\text { stress, } \sigma_{u, \text { sup }}\end{array}$ & $\mathrm{MPa}$ & 3.00 & -0.68 & 0.91 & 0.78 & 2.07 & -0.59 & 0.48 & 0.41 & 2.35 & -0.65 & 0.69 & 0.55 \\
\hline $\begin{array}{l}\text { Central ultimate stress, } \\
\sigma_{u, \text { entr }}\end{array}$ & $\mathrm{MPa}$ & 3.71 & -0.69 & 0.91 & 0.79 & 2.66 & -0.50 & 0.50 & 0.43 & 2.97 & -0.59 & 0.69 & 0.56 \\
\hline $\begin{array}{l}\text { Inferior ultimate stress, } \\
\sigma_{u, \text { inf }}\end{array}$ & $\mathrm{MPa}$ & 3.00 & -0.66 & 0.91 & 0.78 & 1.97 & -0.55 & 0.49 & 0.43 & 2.27 & -0.62 & 0.71 & 0.57 \\
\hline Young's modulus, $E$ & $\mathrm{MPa}$ & 95.6 & -0.55 & 0.79 & 0.71 & 67.4 & -0.52 & 0.36 & 0.32 & 75.8 & -0.56 & 0.57 & 0.48 \\
\hline $\begin{array}{l}\text { Vertebral proportional } \\
\text { stiffness, } \mathrm{K}_{p}\end{array}$ & $\mathrm{~N} / \mathrm{mm}$ & 4888 & -0.38 & 0.53 & 0.40 & 3824 & -0.23 & 0.32 & 0.36 & $4 \mid 40$ & -0.32 & 0.44 & 0.39 \\
\hline $\begin{array}{l}\text { Vertebral ultimate } \\
\text { stiffness, } K_{u}\end{array}$ & $\mathrm{~N} / \mathrm{mm}$ & 4315 & -0.58 & 0.73 & 0.59 & 2925 & -0.35 & 0.34 & 0.33 & 3337 & -0.47 & 0.55 & 0.43 \\
\hline
\end{tabular}




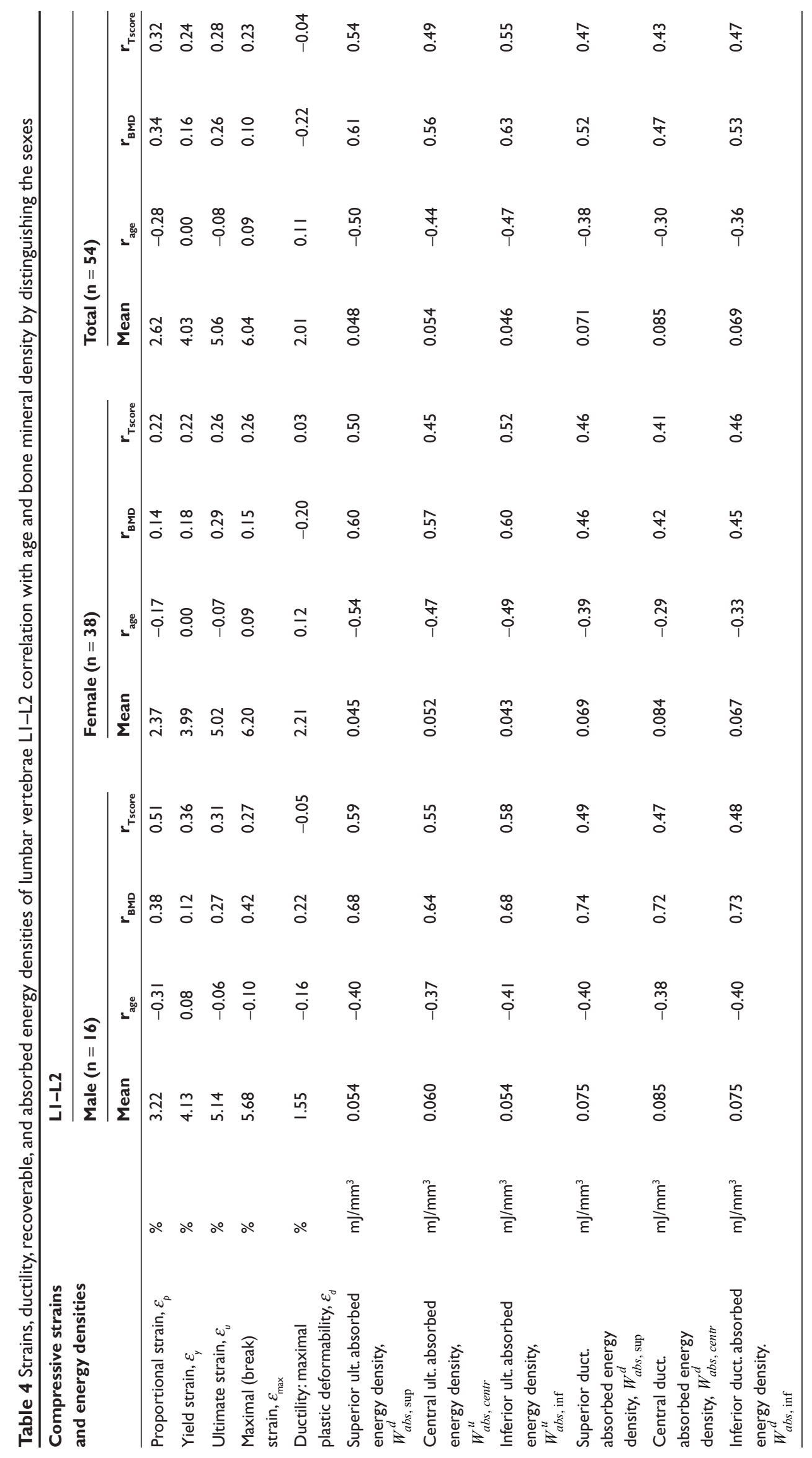




\section{A}

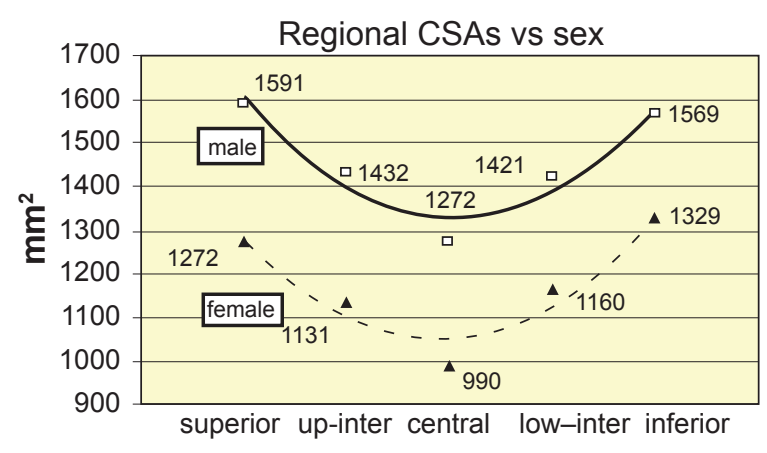

C

Yearly increase of regional CSAs between 43-93 yrs

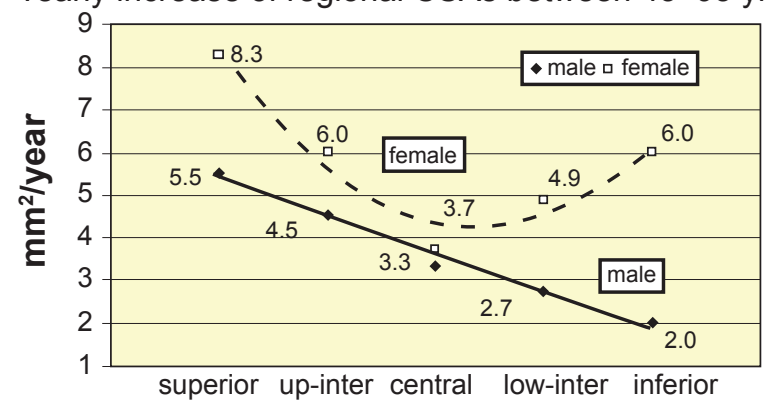

\section{B}

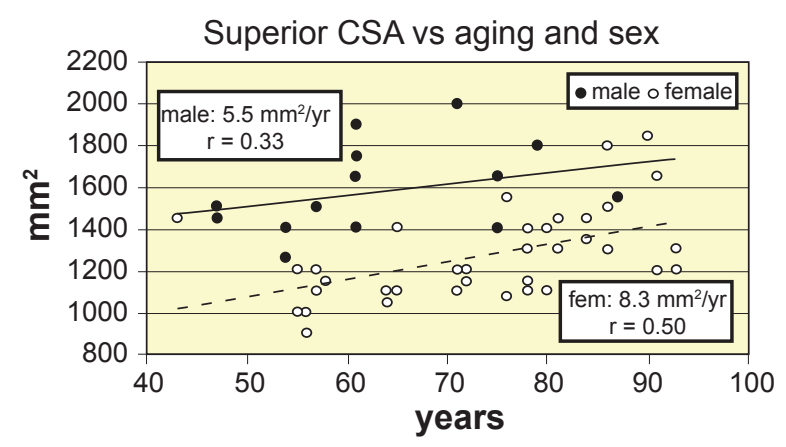

D

Total increase of regional CSAs during 50 yrs (43-93)

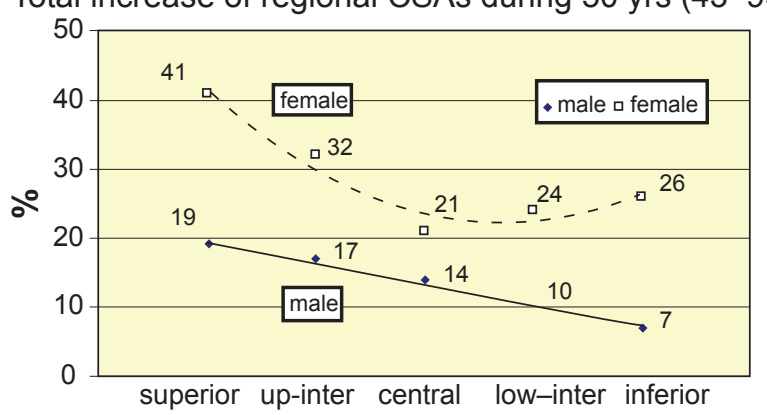

Figure 2 Regional cross sectional areas versus aging and sex. A) Regional CSAs. B) Superior CSA vs aging and sex. C) Yearly increase of regional CSAs vs sex. D) Total increase of regional CSAs vs sex.

Abbreviation: CSA, cross-sectional area.

load, ultimate stress, Young's modulus and ultimate stiffness of vertebrae L1-L2, by distinguishing the sexes. The strong correlation of men supports the linear approximation for them, however, the moderate or weak correlation of women indicate the need of nonlinear approximation for them. Indeed, the age-related loss of vertebral bone density of sexes seen in Figure 8a verifies this assumption. Linear regression is applied for both sexes in Figure 8a, while in Figure 8b quadratic approximation yielded better correlation for women.

Finally, in Figure 9 the age-correlation of strength parameters of women is improved by applying quadratic approximation for ultimate load, stress, Young's modulus, and vertebral stiffness in Figures 9a, 9b, 9c, and 9d, respectively.

\section{Discussion}

\section{Shape of stress-strain diagrams of vertebrae}

Related to the shape of the linearized diagrams in Figure 1, we observed that type $A$ belonged to the elder and type $B$ to the relatively younger population. Strong correlation was found between aging and shape type of load-displacement diagrams: $r=0.68$ for men, $r=0.62$ for women and $r=0.66$ for the total set of specimens.
After the first failure the loading process was continued up to the final collapse when the load-displacement curves were broken off. In aspect of the shape of the experimental load-displacement diagrams after the first failure, Lindahl (1976) analyzed the trabecular bone of lumbar vertebrae L1-L4, based on compressive test of cubic blocks cut from the spongy bone with removed bone marrow. He distinguished three types of shape of curves after reaching the maximum load: a declining, a constant and a rising line. He found $13 \%$ were decreasing, $49 \%$ were constant, and $38 \%$ were increasing shape. By the same classification, we have found for total vertebral bodies L1-L2 47\% were decreasing, $28 \%$ were constant, and $25 \%$ were increasing shape. The main reasons of the weaker results of our experiments were the strongly osteoporotic elderly population; for men over 60 and for women over 80 the curves were exclusively decreasing after the first failure.

\section{Regional CSAs of vertebrae versus aging and sex}

Only slight differences were found in the geometrical and mechanical properties of vertebrae L1 and L2 (Table 1). Cross sections were about $2 \%$, volumes about $10 \%$ smaller 
A

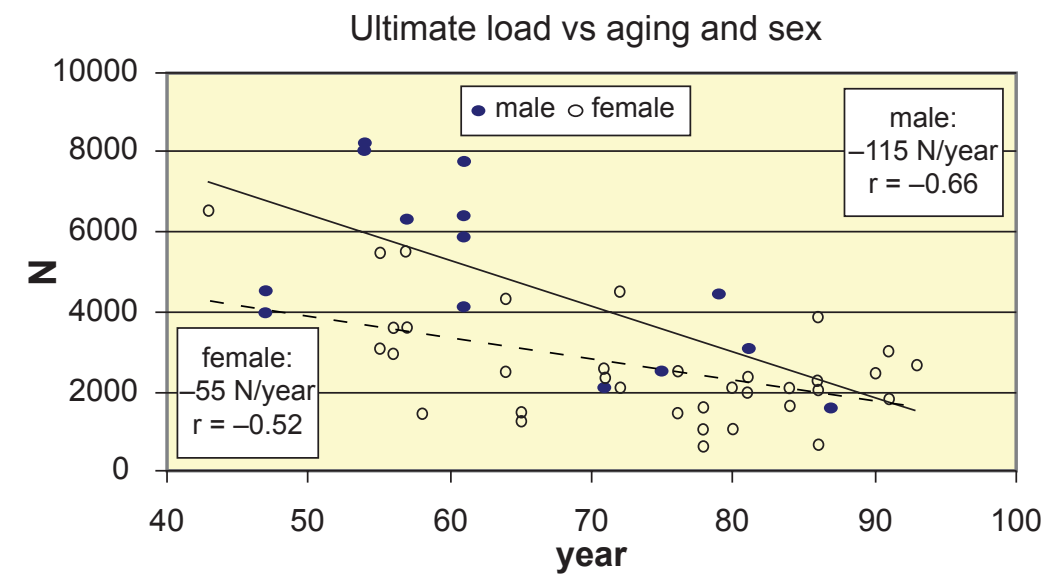

B

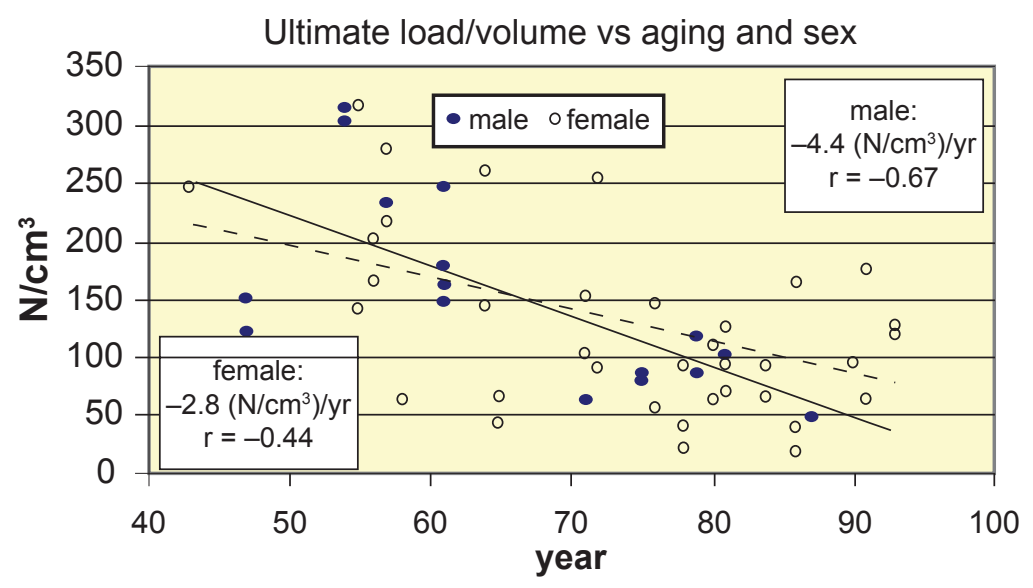

Figure 3 Decrease of ultimate load and load/volume of vertebrae LI-L2 vs aging and sex.A) Decrease of ultimate load vs aging and sex. B) Decrease of ultimate load/volume vs aging and sex.

in L1, failure loads, stresses and energy absorption capacity were practically the same in L1 and L2. Consequently, L1 and L2 were handled together.

Significant differences were found in regional CSAs of vertebrae versus sexes (Table 2, Figure 2). CSAs were $15 \%-20 \%$ smaller in women in all regions (Figure 2a). The yearly increase of regional CSAs between $43-93$ years was different for males and females (Figures $2 b$ and $2 c$ ), with small age-correlation of males and moderate for females (Table 2). The total increase of regional CSAs during 50 years between $43-93$ years was about two-folds higher for women and it was higher in the superior level for both sexes (Figure 2d).

For vertebrae L1-L3 Mosekilde and Mosekilde (1986) found $25 \%-30 \%$ CSA increase from the age of 20 to 80 years. For vertebrae L2 of 90 normal individuals aged 15-91 years Mosekilde and Mosekilde (1990) obtained
25\%-30\% increase in CSA with aging in males, and no change in females. Again, Mosekilde (2000) stated that men showed age-related CSA increase while women did not. We obtained both for women and men a significant age-related CSA increase in strongly osteoporotic population (Figure 2b). Moreover, in all region women had higher yearly increase than men, stronger in superior level in both sexes, minimal in men in the inferior level and in women in the central level (Figure 2c). Again, the total increase \% of regional CSA during 50 years between 43-93 years was smaller for males (Figure 2d).

\section{Sex-related compressive strength parameters of vertebrae}

Mean proportional and ultimate loads were about $45 \%-50 \%$ smaller for women, this ratio decreased to $15 \%-25 \%$ in size-corrected load/volume case (Figure 3). Proportional 


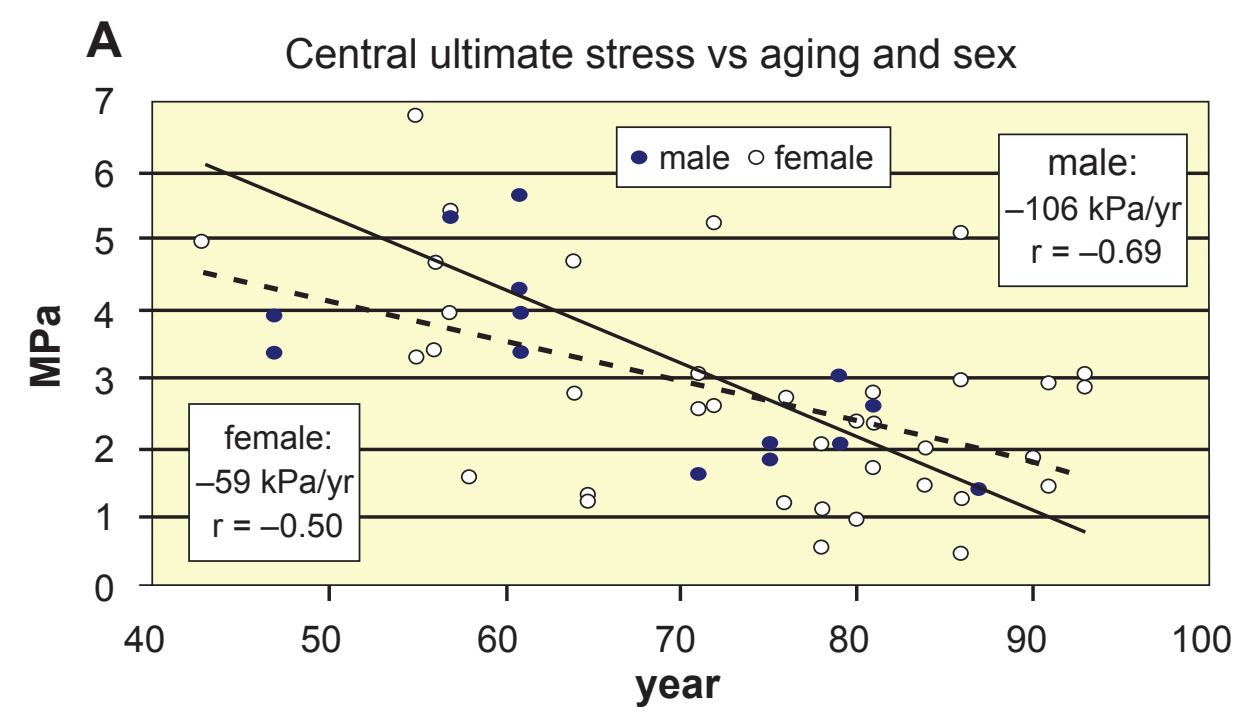

B
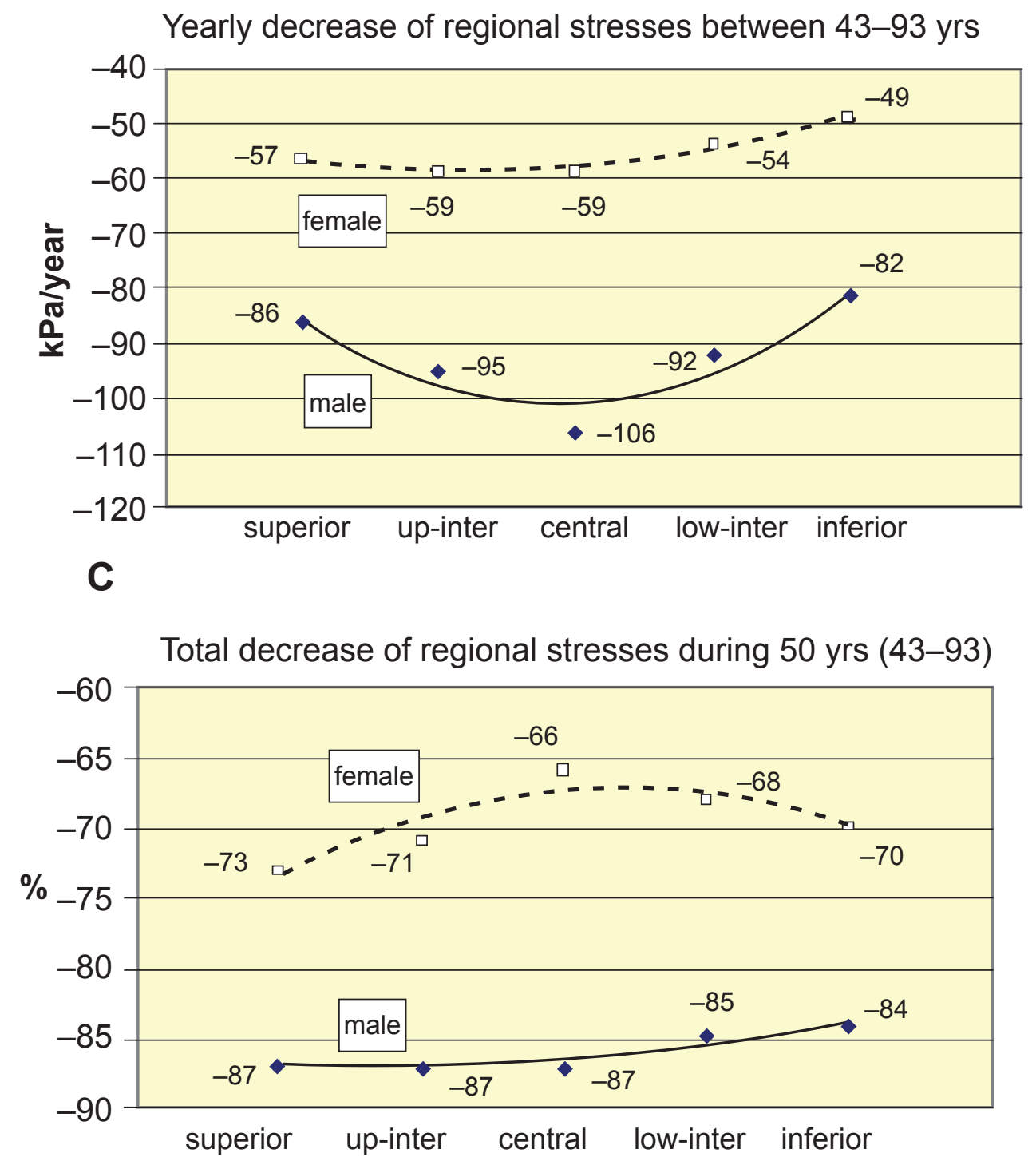

Figure 4 Decrease of regional ultimate stresses of vertebrae LI-L2 vs aging and sex. A) Decrease of central ultimate stresses vs aging and sex. B) Yearly decrease trends of regional ultimate stresses vs aging and sex. C)Total decrease \% of regional ultimate stresses during 50 years between $43-93$ years. 


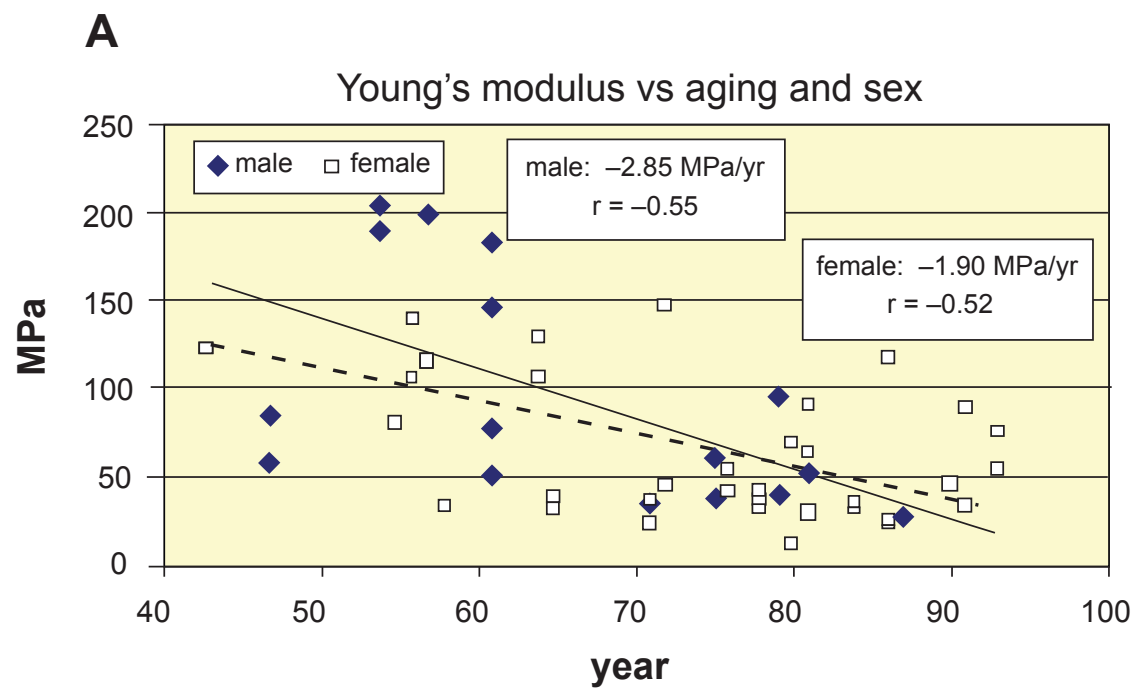

B

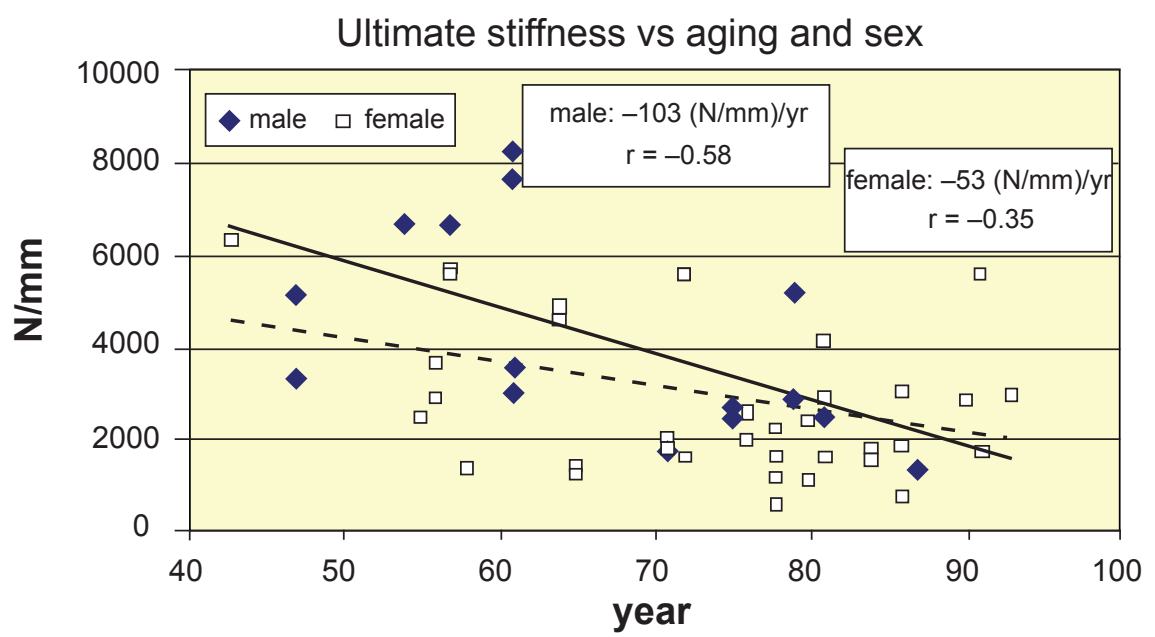

Figure 5 Decrease of Young's modulus and ultimate stiffness of vertebrae LI-L2 vs aging and sex. A) Decrease of Young's modulus vs aging and sex. B) Decrease of ultimate stiffness vs aging and sex.

stresses were about $35 \%$, ultimate stresses about $30 \%$ smaller for women in any levels (Figure 4b). These stresses were $20 \%-25 \%$ higher in the central region for both sexes.

For total vertebrae L1-L3 of subjects aged 15-87 years, Mosekilde and Mosekilde (1986) found the maximum compressive stresses to be between 1.5-7.8 $\mathrm{MPa}$ and Tanaka and colleagues (2001) found the vertebral ultimate stress to be between 0.14-4.54 MPa. Our stresses agree with these results. Duan and colleagues (2001) obtained mean peak loads $3754 \mathrm{~N}$ for men and $3051 \mathrm{~N}$ for women in L3 of healthy elderly, with no gender difference in mean stresses: $3.17 \mathrm{MPa}$ for men and 3.22 MPa for women. Similarly, for vertebral bodies L3 aged 18-96 years Ebbesen and colleagues (1999a) obtained lower maximum compressive load and nearly equal stress for women: $6.5 \mathrm{kN}$ and 4.6 MPa for males and $5.1 \mathrm{kN}$ and 4.5 MPa for females, respectively. We obtained smaller stresses for women than for men, at any age, in any region in strongly osteoporotic subjects with older women.

We found the Young's moduli and vertebral stiffness of women about 25\%-30\% smaller (Table 3). Proportional strains were about $25 \%$ smaller in women; yield and ultimate strains quasi equal in sexes; break strains about $35 \%$ higher in women. Ductility was about $40 \%$ higher in women. Consequently, small strains were higher in males, large strains were higher in females (Table 4).

Lindahl (1976) and Hansson and colleagues (1987) found the proportional stress 1.37-4.0 MPa, proportional strain 6.0\%-6.7\%, Young's modulus 22.8-55.6 MPa, ultimate stress $1.55-4.60 \mathrm{MPa}$, ultimate strain $7.4 \%-9.5 \%$ for vertebral cancellous bone. These results verify that due to 
A

Superior ult. energy density absorptions vs aging, sex

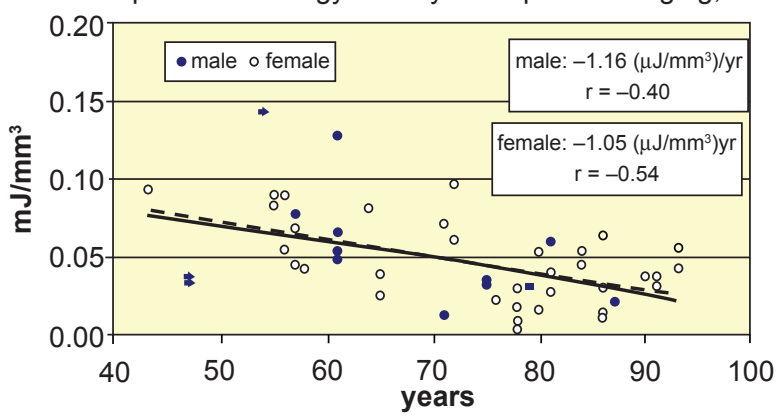

C

Yearly loss of regional energy absorption capacity between 43-93 years

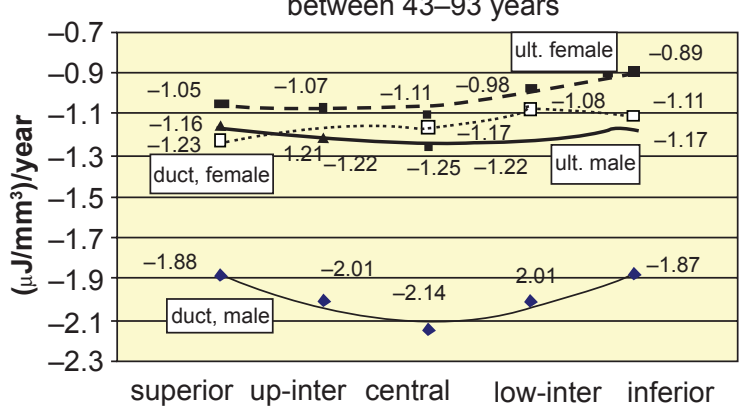

B

Superior duct. energy density absorptions vs aging, sex

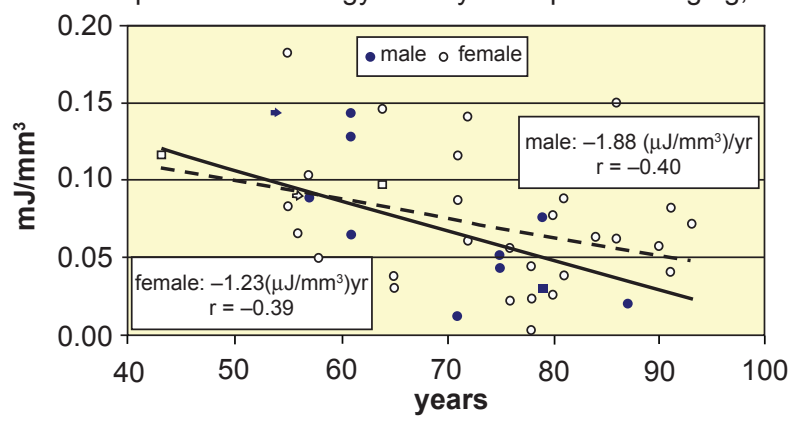

D

Total loss of regional energy absorption capacity during 50 years (43-93)

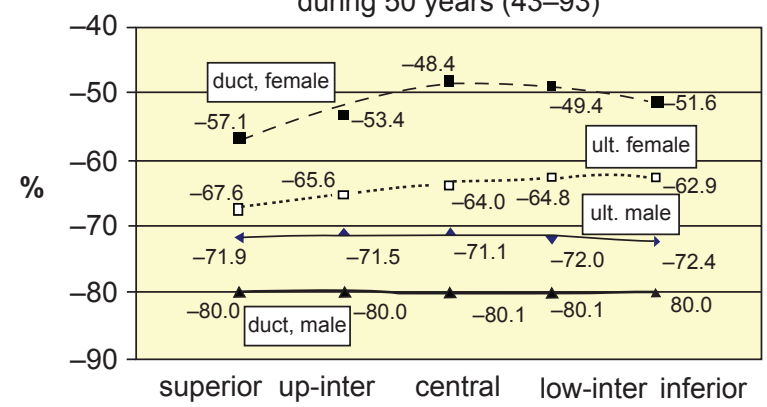

Figure 6 Age- and sex-related decrease of energy absorption capacity of vertebrae LI-L2. A, B) Age-related decline of superior ultimate and ductile energy density absorption versus sexes. C) Yearly loss of regional ultimate and ductile energy absorption capacity. D) Total regional loss of ultimate and ductile energy absorption capacity of sexes during 50 years between $43-93$ years.

\section{A}

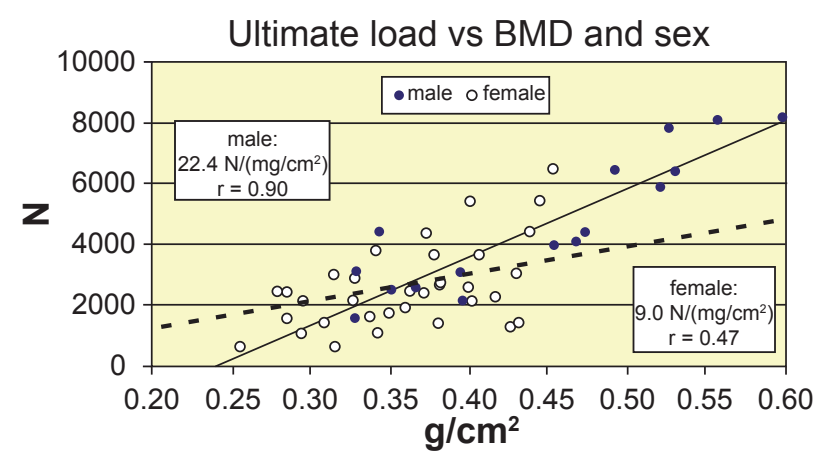

C

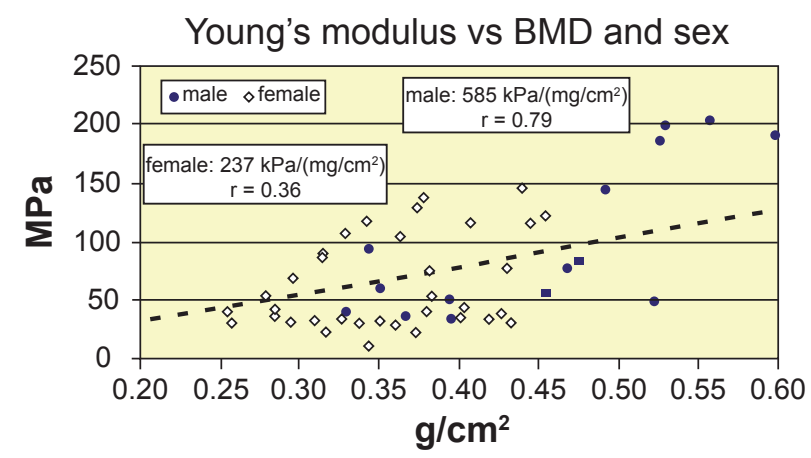

B

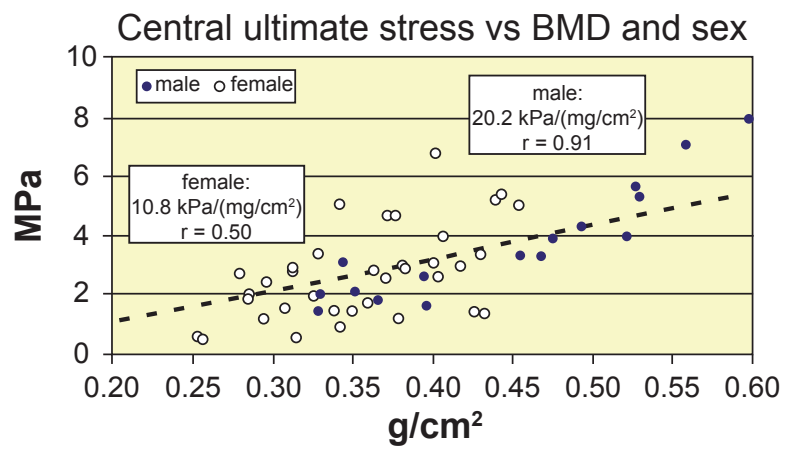

D

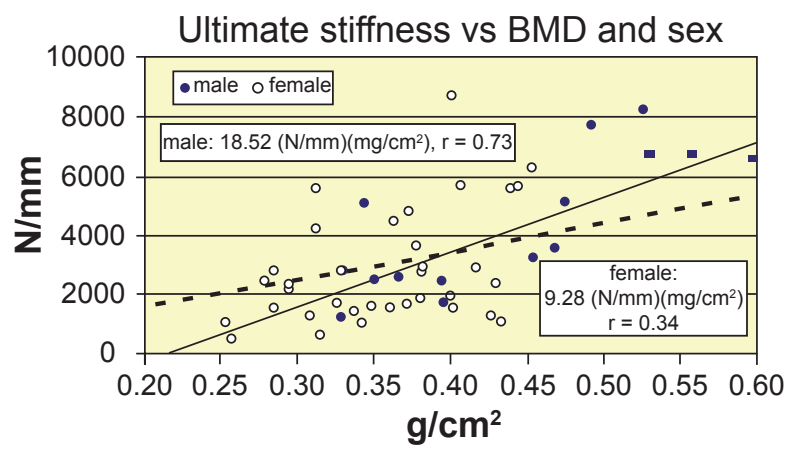

Figure 7 Compressive strength versus BMD. A, B, C, D) Increase of ultimate load, central ultimate stress, Young's modulus, and ultimate stiffness vs BMD, respectively. Abbreviation: BMD, bone mineral density. 


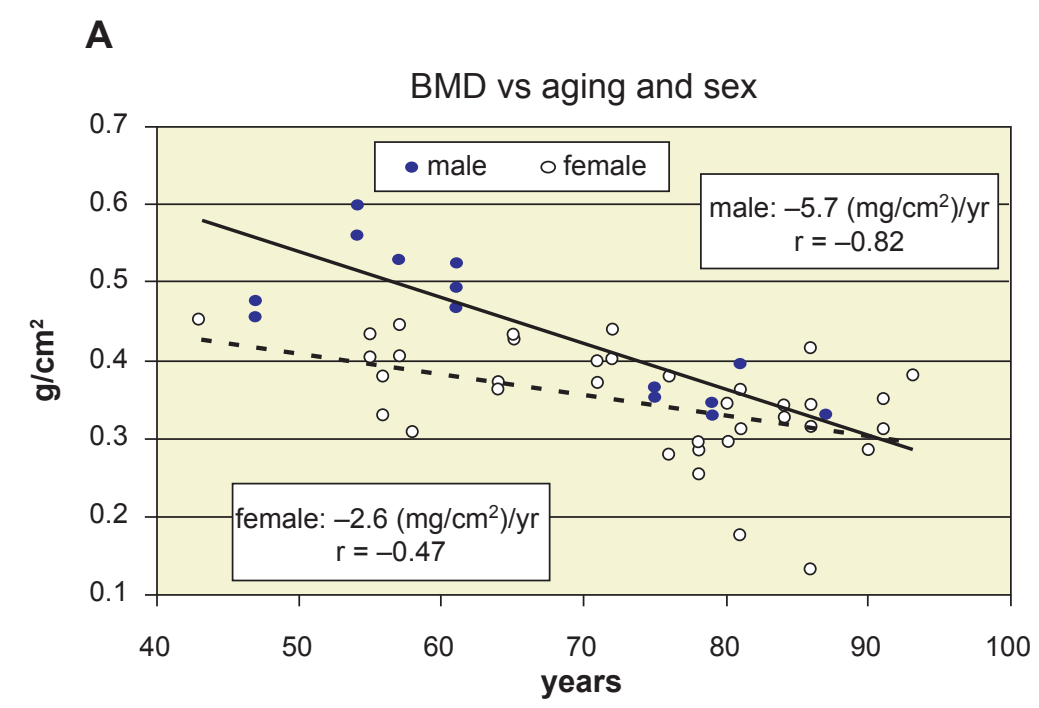

\section{B}

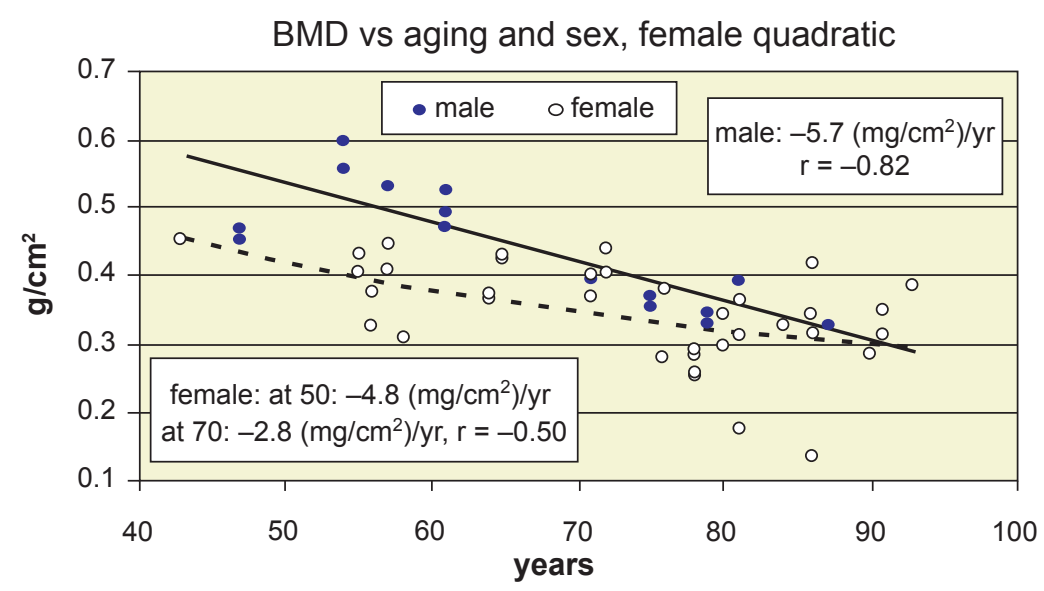

Figure 8 Bone mineral density (BMD) versus aging and sex. A) linear decline of BMD with aging and sex. B) quadratic approximation for women with yearly decline trends at age 50 and 70 years.

the high ductility, the trabecular bone is responsible for the energy absorption capacity of vertebrae to avoid injury in accidental loading situations.

We obtained the recoverable elastic energy density at proportional stresses about $35 \%-40 \%$ smaller in females in all regions. The ultimate absorbed energy density was about $20 \%$ higher in men, while the final ductile energy absorption capacity was quasi-equal for sexes in all regions (Table 4), and was slightly higher in the central level.

\section{Age- and sex-related compressive strength parameters of vertebrae}

By applying linear regression, the loss of ultimate load in the total group was $87 \mathrm{~N} / \mathrm{year}$, that is $1.54 \%$ starting at 43 ; and the total loss was $77 \%$ between $43-93$ years. The decrease slope of failure load was quasi the double for males than for females (Figure 3a), however, this slopes were $1.59 \%$ yearly loss for males, and $1.30 \%$ for females. During the age-span of 43-93 years men lost $79 \%$, women lost $65 \%$ of their loadbearing capacity, with strong correlation for men $(\mathrm{r}=-0.66$, $\mathrm{p}<0.01)$ and moderate for women $(\mathrm{r}=-0.52, \mathrm{p}<0.001)$. Similar tendencies were obtained for proportional and sizecorrected loads (Table 3).

We found the yearly loss of ultimate stresses at the superior, central and inferior levels $86,106,82 \mathrm{kPa} /$ years, namely, $1,74 \%, 1,73 \%, 1,68 \%$ loss/year for males; 57,59 , $49 \mathrm{kPa} /$ year, that is, $1.48 \%, 1.31 \%, 1.41 \%$ loss/year for females (Figures $4 \mathrm{a}$ and $4 \mathrm{~b}$ ). The total loss in these regions was $87 \%, 87 \%, 84 \%$ for males, and $73 \%, 66 \%, 70 \%$ for females during 43-93 years (Figure 4c). Ultimate 
A

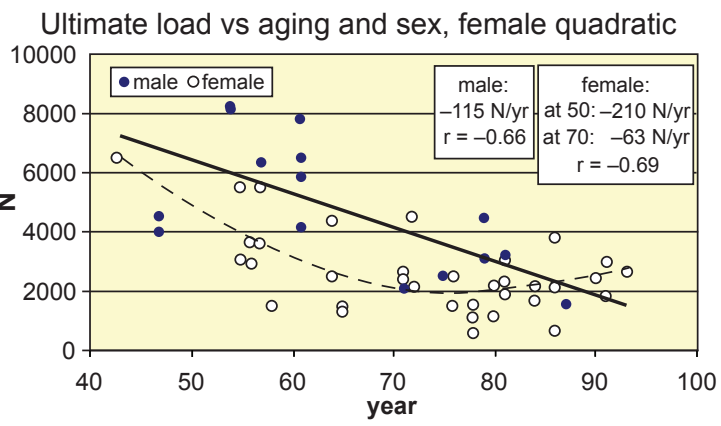

C

Young's modulus vs aging and sex, female quadratic

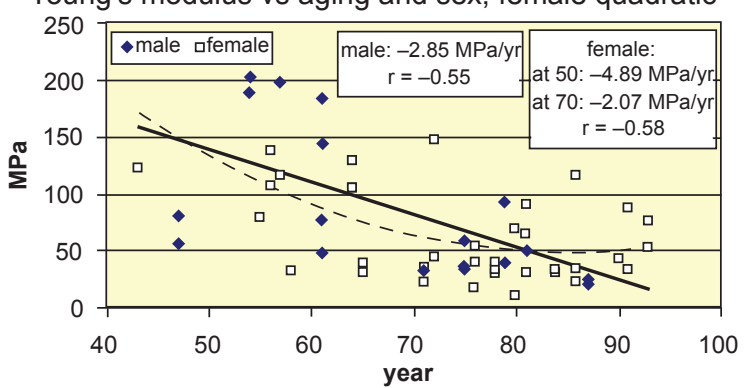

\section{B}

Central ultimate stress vs aging and sex, female quadratic

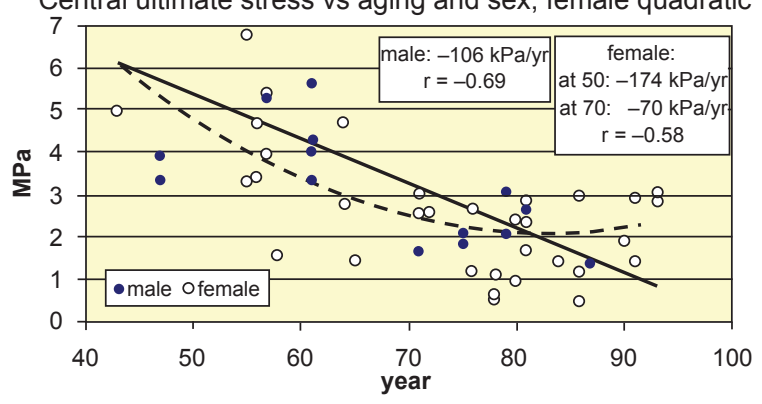

D

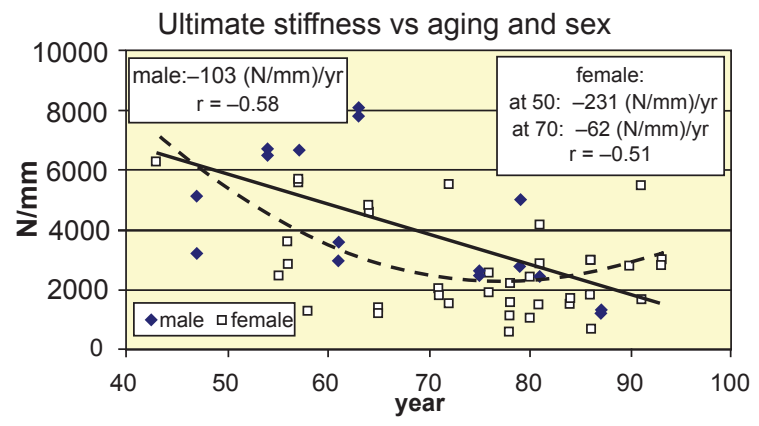

Figure 9 Age-related nonlinear approximation of strength parameters for women. A, B, C, D) Quadratic approximation of age-related decline function of ultimate load, central ultimate stress, Young's modulus, and ultimate stiffness of women, respectively.

stresses showed a bit higher age-correlation than proportional stresses in all regions (Table 3 ). Negative age-correlation of stresses were strong for men $(r=0.60-0.69, \mathrm{p}<0.01)$ and moderate for women $(\mathrm{r}=0.42-0.59, \mathrm{p}<0.001)$. For ultimate stresses of lumbar vertebrae Tanaka and colleagues (2001) found the age-correlation significant $(\mathrm{r}=-0.66)$. Mosekilde and colleagues (1987) obtained higher correlation $(\mathrm{r}=-0.81)$ for normal individuals aged 15-87 years. Mosekilde and colleagues (2000) stated that the strength of spinal trabecular bone declined by a factor of 4-5 from 20 to 80 years. Indeed, we obtained a factor about 5 for men and about 4 for women between 43-93 years.

By using linear regression, for the central part of L3 (51 females and 50 males, aged 59 and 55 yrs) Ebbesen and colleagues (1999a) found the loss of maximum compressive loads and stresses as $100 \mathrm{~N} /$ year $(\mathrm{r}=-0.76)$ and $73 \mathrm{kPa} /$ year $(\mathrm{r}=-0.74)$ for males; $90 \mathrm{~N} /$ year $(\mathrm{r}=-0.77)$; and $88 \mathrm{kPa} /$ year $(\mathrm{r}=-0.8)$ for females. We obtained similar results for men, but lower strength loss for women, but for a strongly osteoporotic population, where women were about 10 years older.

According to McCaldren and colleagues (1997) the compressive strength of femoral cancellous bone decreases by $8.5 \%$ each decade. We found about $14 \%$ for women and $17 \%$ for men, but for strongly osteoporotic lumbar vertebrae. Mosekilde (1998) mentioned that the decline in strength of the whole vertebral body during normal aging for both sexes was $70 \%-80 \%$. This is in good agreement with our results.

We found the yearly loss of Young's moduli $2.85 \mathrm{MPa} /$ years namely, $1.80 \%$ loss/year for males; $1.90 \mathrm{MPa} /$ year, that is, $1.50 \%$ loss/year for females, respectively (Figure 5a). The total loss during 43-93 years at these levels was 90\% for males, and $75 \%$ for females. Age-correlation was moderate for both males $(\mathrm{r}=-0.55, \mathrm{p}<0.05)$ and females $(\mathrm{r}=-0.52$, $\mathrm{p}<0.01$ ), which was in good agreement with Mori (1994) who found $r=-0.527$ correlation for L3.

We can state that there is no definite correlation between strains and aging (Table 4).

The yearly loss of absorbed final ductile energy density at the superior, central and inferior levels were 1.88, 2.14, $1.87 \mu \mathrm{J} / \mathrm{mm}^{3}$, namely, equally $1.60 \%$ loss/year for males; $1.23,1.17,1.11 \mu \mathrm{J} / \mathrm{mm}^{3}$, that is, $1.14 \%, 0.97 \%, 1.03 \%$ loss/year for females (Figures $6 \mathrm{~b}$ and $6 \mathrm{c}$ ). The total loss of ductile energy absorption capacity during 43-93 years in these regions was equally $80 \%$ for males, and $57 \%, 48 \%$, $52 \%$ for females (Figure 6d). While the age-correlation for reversible elastic energy density was strong for men 
(about $-0.60, \mathrm{p}<0.02$ ) and weak or moderate for women (about $-0.35, \mathrm{p}<0.05$ ), for the irreversible absorbed energy density was moderate for both sexes, in all regions (Table 4). Mosekilde and colleagues (1987) obtained for L1 vertebral centrum of 42 normal people that from 20 to 80 years the decline in compressive stress, stiffness, and energy absorption capacity was $75 \%-80 \%$, which was in good agreement with our results.

\section{Nonlinear approximation of age-related decline of strength parameters of women}

Some papers state the age-related decline of BMD as one of the most important responsible factors for compressive load-bearing capacity of vertebrae. Indeed, significant positive correlation was found between bone mineral density (BMD) and compressive strength by McBroom and colleagues (1985) (strength $r=0.82$ ); Lang and colleagues (1988) (strength $r=0.72$ ); Augat and colleagues (1998) (stiffness $r=0.73$ ); Edmondston and colleagues (1997) (failure load $r=0.82-0.86$, failure stress $r=0.73-0.78)$; furthermore, see Jiang and colleagues (1998) (elastic modulus $r=0.76$ ), Link and colleagues (1998), Millard and colleagues (1998), Ebbesen and colleagues (1999b).

We have found similar overall correlations with areal BMD (without distinguishing the sexes): ultimate load $r=0.75(p<0.0001)$, ultimate stress $r=0.69(p<0.0001)$, Young's modulus $\mathrm{r}=0.57$ ( $\mathrm{p}<0.001)$, ultimate stiffness $\mathrm{r}=0.55(\mathrm{p}<0.001)$ and ultimate energy absorption capacity $r=0.56(p<0.001)$. However, by distinguishing the sexes, these correlations significantly bifurcate: even stronger for men: $r=0.90,0.91,0.79,0.73$, and 0.64 , and modest for women: $r=0.47,0.50,0.36,0.34$, and 0.57 , respectively. Consequently, linear regression is acceptable for men, while for women, nonlinear approximation may improve the correlation. Indeed, $r=0.47$ of ultimate load (Figure $7 \mathrm{a}$ ) can be improved to $r=0.58$ by applying second order approximation for women.

Ebbesen and colleagues (1999a) concluded that the strength decrease of vertebral body during lifelong aging was twice as large as the density decrease, corresponding to the fact that the ideal relation between strength and density is a power function. Mosekilde and colleagues (1987) observed 48\%-50\% decline in ash density from age 20 to 80 years, compared to $75 \%-80 \%$ decrease in strength parameters. These statements seems to be confirmed by our results, as well, but distinguishing the sexes. In Figure $8 \mathrm{a}$ the age-related decline of BMD is illustrated, by applying linear regression for the sexes. The yearly age-related loss of BMD is $5.7 \mathrm{mg} / \mathrm{cm}^{2}$, namely $0.99 \%$ loss/year for males; and $2.6 \mathrm{mg} / \mathrm{cm}^{2}$, that is, $0.60 \%$ loss $/$ year for females. Thus, the total loss is $49 \%$ for males, and $30 \%$ for females, during 50 years. At the same time, as seen above, the total loss of failure load, failure stress, Young's modulus and energy absorption capacity was in average $80 \%, 85 \%, 90 \%$, and $80 \%$ for men; $65 \%, 70 \%, 75 \%$. and $50 \%$ for women, respectively, that are about the double of the loss of BMD, but smaller than double (1.7 times) for men and larger than double (2.2 times) for women. Thus, women lose more than double of their strength than density. Is it true? Or is the linear regression incorrect for them, since the loss of density and strength is disproportional in their life?

We concluded that linear approximation is evident for men and nonlinear for women, supported by the correlation between BMD and age (Figure 8a): very strong correlation for men $(\mathrm{r}=-0.82, \mathrm{p}<0.0001)$ and moderate for women $(r=-0.47, p<0.01)$. Namely, different decline trends must be distinguished for certain life periods of women. A lot of authors suggest this distinction.

Riggs and colleagues (1981) suggested that disproportionate loss of trabecular bone is a distinguishing characteristic of spinal osteoporosis. Blunt and colleagues (1994) concluded that BMD decreased in old age in both sexes, but the slope was steeper in women aged 50-59 years than in older women, 60-98 years. Diaz Curiel and colleagues (1997) found in females the highest value of BMD within 30-39 years, being significantly lower after the age of 49 years. Warming and colleagues (2002) obtained that lumbar bone loss in women before menopause was smaller than $0.004\left(\mathrm{~g} / \mathrm{cm}^{2}\right) /$ year that nearly tripled in the early postmenopausal years. Greer and colleagues (2003) offered a mathematical model for women, based on the assumption that bone loss can be described as an exponential decay process that begins at menopause. Mazzuoli and colleagues (2006) studied the annual changes of lumbar BMD in 120 healthy pre- and post-menopausal women aged 45-74 years. Results indicated that BMD decrease trend was not constant in time.

For age-BMD relation of women, we applied quadratic approximation (Figure 8b), yielding a succesively changing decline trend starting at menopause. Thus, at the age of $50,60,70$, and 80 years, the decrease trends were 5.6, 4.2, $2.8,1.4\left(\mathrm{mg} / \mathrm{cm}^{2}\right) /$ year, respectively. By applying quadratic approximation for age-related ultimate load, stress, Young's modulus and energy absorption functions, too, the age-correlation could be improved (Figure 9). Mosekilde (1998) supports these results: in men she found smooth stress decrease, while in women the most significant decrease 
happened between 40-50 years. Kim and Al-Hassani (2002) used also nonlinear approximation to illustrate the sexrelated difference between aging and mechanical properties of vertebrae.

In conclusion, this experimental study showed the ageand sex-related variations of compressive strength parameters of vertebral bodies L1-L2 of osteoporotic elderly. Proportional and failure loads and regional stresses; elastic, plastic and ductile strains; Young's moduli and regional energy absorption capacity were considered. Significant sex-differences were found in the geometry and compressive load-bearing properties of vertebrae. Failure load was about $45 \%-50 \%$ smaller for women, in size-corrected case this ratio decreased to $15 \%-25 \%$. Proportional and ultimate stresses were 20\%-25\% higher in the central region for both sexes, and were about $30 \%-35 \%$ smaller for women in all levels. Young's moduli were about $30 \%$ smaller in women. Small strains were higher in males, large strains were higher in females. The absorbed ultimate energy density was about $20 \%$ higher in men, and was nearly equal in all regions. However, the final ductile energy absorption capacity of vertebrae was higher in the central level and was quasi equal for sexes in all regions. The total loss of failure load, stress, Young's modulus and energy absorption capacity during the 50 years between $43-93$ were in average $80 \%, 85 \%, 90 \%$, $80 \%$ for men and $65 \%, 70 \%, 75 \%, 50 \%$ for women, respectively. We concluded that statical variables (loads, stresses) showed significant correlation; mixed variables (stiffness, Young's modulus, energy) showed moderate correlation; kinematical variables (displacements, strains) showed no correlation with age. We obtained better approximation for women if applying quadratic age-related decline of BMD and strength parameters in all regions, yielding the highest decline just after menopause, with gradually decreasing loss trends during further aging.

\section{Acknowledgments}

The present study was supported by the projects OTKA T046755, ETT 257/2000 and TéT GR-17/03.

\section{References}

Augat P, Link T, Lang TF, et al. 1998. Anisotropy of the elastic modulus of trabecular bone specimens from different anatomical locations. Med Eng Phys, 20:124-31.

Banse X, Devogelaer JP, Munting E, et al. 2001. Inhomogeneity of human vertebral cancellous bone: systematic density and structure patterns inside the vertebral body. Bone, 28:563-71.

Blunt BA, Klauber MR, Barrett-Connor EL, et al. 1994. Sex differences in bone mineral density in 1653 men and women in the sixth through tenth decades of life: the Rancho Bernardo Study. J Bone Miner Res, 9:1333-8.
Briggs AM, Greig AM, Wark JD, et al. 2004. A review of anatomical and mechanical factors affecting vertebral integrity. Int $\mathrm{J} \mathrm{Med} \mathrm{Sci,}$ 1:170-80.

Diaz Curiel M, Carrasco de la Pena JL, Honorato Perez J, et al. 1997. Study of bone mineral density in lumbar spine and femoral neck in a Spanish population. Multicentre Research Project on Osteoporosis. Osteoporosis Int, 7:59-64.

Duan Y, Seeman E, Turner CH. 2001. The biomechanical basis of vertebral body fragility in men and women. J Bone Miner Res, 16:2276-83.

Ebbesen EN, Thomsen JS, Beck-Nielsen H, et al. 1999a. Age- and genderrelated differences in vertebral bone mass, density, and strength. J Bone, Miner Res, 14:1394-403.

Ebbesen EN, Thomsen JS, Beck-Nielsen H, et al. 1999b. Lumbar vertebral body compressive strength evaluated by dual-energy X-ray absorptiometry, quantitative computed tomography, and ashing. Bone. 25:713-24.

Edmondston SJ, Singer KP, Day RE, et al. 1997. Ex vivo estimation of thoracolumbar vertebral body compressive strength: the relative contributions of bone densitometry and vertebral morphometry. Osteoporosis Int, 7:142-8.

Gong H, Zhang M, Yeung HY, et al. 2005. Regional variations in microstructural properties of vertebral trabeculae with aging. J Bone Miner Metabol, 23:174-80.

Greer W, Smith R, Shipman AJ. 2003. A multi-exponential model of postmenopausal decline in vertebral bone mineral density: a new approach to the BMD reference range. J Clin Densitom, 6:113-24.

Hansson TH, Keller TS, Panjabi MM. 1987. A study of the compressive properties of lumbar vertebral trabeculae: effects of tissue characteristics. Spine, 12:56-62.

Jiang Y, Zhao J, Augat P, et al. 1998. Trabecular bone mineral and calculated structure of human bone specimens scanned by peripheral quantitative computed tomography: relation to biomechanical properties. J Bone Miner Res, 13:1783-90.

Keaveny TM, Yeh OC. 2002. Architecture and trabecular bone - toward an improved understanding of the biomechanical effects of age, sex and osteoporosis. J Musculoskelet Neuronal Interact, 2:205-8.

Keller TS, Hansson TH, Abram AC, et al. 1989. Regional variations in the compressive properties of lumbar vertebral trabeculae: Effects of disc degeneration. Spine, 14:1012-9.

Keller TS, Moeljanto E, Main JA, et al. 1992. Distribution and orientation of bone in the human lumbar vertebral centrum. J Spinal Disord, 5:60-74.

Kim HS, Al-Hassani ST. 2002. A morphological model of vertebral trabecular bone. J Biomech, 35:1101-14.

Lang SM, Moyle DD, Berg EW, et al. 1998. Correlation of mechanical properties of vertebral trabecular bone with equivalent mineral density as measured by computed tomography. J Bone Joint Surg Am, 70:1531-8.

Link TM, Majumdar S, Lin JC, et al. 1998. A comparative study of trabecular bone properties in the spine and femur using high resolution MRI and CT. J Bone Miner Res, 13:122-32.

Lindahl O. 1976. Mechanical properties of dried defatted spongy bone. Acta Orthop Scand, 47:11-6.

Mazzuoli G, Diacinti D, D'Erasmo E, et al. 2006. Cyclical changes of vertebral body heights and bone loss in healthy women after menopause. Bone, 38:905-10.

McBroom RJ, Hayes WC, Edwards WT, et al. 1985. Prediction of vertebral body compressive fracture using quantitative computed tomography. J Bone Joint Surg, 67A:1206-14.

McCaldren RW, McGeough JA, Court-Brown CM. 1997. Age-related changes in the compressive strength of cancellous bone. The relative importance of changes in density and trabecular architecture. J Bone Joint Surg Am, 79:421-7.

Millard J, Augat P, Link TM, et al. 1998. Power spectral analysis of vertebral trabecular bone structure from radiographs: orientation dependence and correlation with bone mineral density and mechanical properties. Calcif Tissue Int, 63:482-9. 
Mori S. 1994. Effect of aging on compressive strength of lumbar trabecular bone in hemodialyzed and non-hemodialyzed patients. Nippon Jinzo Gakkai Shi, 36:752-61.

Mosekilde L. 1998. The effect of modelling and remodelling on human vertebral body architecture. Technol Health Care, 6:287-97.

Mosekilde L. 2000. Age-related changes in bone mass, structure, and strength effects of loading, Zeitschrift für Rheumatologie, 59(Suppl 1):1-9.

Mosekilde L, Mosekilde L. 1986. Normal vertebral body size and compressive strength: relations to age and to vertebral and iliac trabecular bone compressive strength. Bone, 7:207-12.

Mosekilde L, Mosekilde L. 1990. Sex differences in age-related changes in vertebral body size, density and biomechanical competence in normal individuals. Bone, 11:67-73.

Mosekilde L, Ebbesen EN, Tornvig L, et al. 2000, Trabecular bone structure and strength - remodelling and repair. J Musculoskelet Neuronal Interact, 1:25-30.
Mosekilde L, Mosekilde L, Danielsen CC. 1987. Biomechanical competence of vertebral trabecular bone in relation to ash density and age in normal individuals. Bone, 8:79-85.

Riggs BL, Wahner HW, Dunn WL, et al. 1981. Differential changes in bone mineral density of the appendicular and axial skeleton with aging: relationship to spinal osteoporosis. J Clin Invest, 67:328-35.

Tanaka Y, Kokubun S, Sato T, et al. 2001. Trabecular domain factor and its influence on the strength of cancellous bone of the vertebral body. Calcif Tissue Int, 69:287-92.

Warming L, Hassager C, Christiansen C. 2002. Changes in bone mineral density with age in men and women: a longitudinal study. Osteoporosis Int, 13:105-12. 
